\title{
DETERMINATION OF ACRYLAMIDE IN THREE DIFFERENT BREAD TYPES BY AN IN-HOUSE VALIDATED LC-MS/MS METHOD
}

\author{
E. AlpöZeN ${ }^{a}$, G. GÜVEN ${ }^{a}$, Ö. ÖZdestaN ${ }^{b *}$ and A. ÜREN ${ }^{c}$ \\ ${ }^{a}$ Izmir Food Control Laboratory, Ministry of Food, Agriculture and Livestock, Bornova Izmir 35100. Turkey \\ ${ }^{\mathrm{b}}$ Food Engineering Department, Engineering Faculty, Ege University, Bornova Izmir 35100. Turkey \\ ${ }^{\mathrm{c}}$ Food Engineering Department, Faculty of Engineering and Architecture, Avrasya University, \\ Yomra Trabzon 61250. Turkey
}

(Received: 3 February 2013; accepted: 3 April 2013)

\begin{abstract}
A rapid and reliable liquid chromatography coupled to tandem mass spectrometry (LC-MS/MS) method was developed for the determination of acrylamide in three different local bread types; wheat bread, bran bread, whole wheat bread. Acrylamide analyses were made in crust parts of the 85 bread samples. The method was linear up to $750 \mu \mathrm{g} \mathrm{kg}^{-1}$ food with a determination coefficient of 0.999 . Recovery rate was found $99.3 \%$ with limit of detection and limit of quantification values of $1.5 \mu \mathrm{g} \mathrm{kg}^{-1}$ and $5.0 \mu \mathrm{g} \mathrm{kg}^{-1}$, respectively. Certified reference materials of crisp bread were analysed and acrylamide contents of these samples were found in the range cited in the certificates. Statistical correlations were investigated between acrylamide contents and protein contents, reducing sugar contents, moisture contents, $\mathrm{pH}$, and colour parameters $\left(\mathrm{L}^{*}, \mathrm{a}^{*}, \mathrm{~b}^{*}\right)$ of bread samples. Sample preparation procedure and chromatographic conditions of acrylamide analysis were investigated in more detail, and a rapid, accurate, precise, and reliable analysis method was developed.
\end{abstract}

Keywords: acrylamide, bread, liquid chromatography tandem mass spectrometry, LC-MS/MS

In early 2002, Swedish National Food Administration (SNFA) and University of Stockholm announced that certain foods that are processed or cooked at high temperatures, such as frying, baking, and roasting, especially carbohydrate-rich foods, contain high levels of acrylamide (CLAEYS et al., 2005). A number of theoretical mechanisms have been proposed for the formation of acrylamide. Maillard browning reaction was reported as the most probable mechanism for the development of acrylamide in cooked foodstuffs (BARUTÇU et al., 2009). Asparagine was found to be the main precursor of acrylamide. Detection of high concentrations of acrylamide is common in heated starch-rich foods, which shows strong relation of acrylamide formation to the sugar content, especially glucose and fructose (Pedreschi et al., 2006; Barutçu et al., 2009).

Acrylamide, a neurotoxic compound, was classified by the International Agency for Research on Cancer (IARC) as probably carcinogenic to human (IARC, 1994). Several analytical methods have been used to quantify acrylamide in foods. Gas chromatography with mass spectrometric detection (GC-MS) with or without derivatization, and highperformance liquid chromatography with tandem mass spectrometry (LC-MS/MS) appear to be the most commonly used methods. GC-MS methods with derivatization are hazardous to health due to bromination, laborious, and time consuming. GC-MS methods without derivatization step appear to be relatively simple, but their drawbacks are the lack of characteristic ions in the mass spectrum. Nowadays, more attention is paid to LC-MS/MS techniques having high sensitivity and saving time. There are also significant differences

\footnotetext{
* To whom correspondence should be addressed.

Phone: +90 232 3111315; fax: +90 232 3427592; e-mail: ozgul.ozdestan@ege.edu.tr
}

0139-3006/\$20.00 @ 2013 Akadémiai Kiadó, Budapest 
between procedures at sample preparation steps, namely extraction of acrylamide from the food matrix and clean-up of the extracts to exclude co-extractive interferences (WENZL et al., 2003; ClAEYs et al., 2005). When the previous studies on acrylamide analysis by LC-MS/MS method are examined, it can be seen that these methods include long extraction and clean-up steps and interfering peaks are observed especially when working with potato-based foods.

Acrylamide concentrations in bread are low, but since consumption is high, bread may still account for $10-20 \%$ of the basic exposure (GROB, 2007). It is reported that almost all the acrylamide was formed in the crust of the bread, the amount of acrylamide increased with both baking time and temperature (ZHANG \& ZHANG, 2007). Bran bread, whole wheat bread, and wheat bread are the mostly consumed bread types in Turkey. Bran bread is preferred for its high dietary fibre content, wheat bread for its sensory properties, whole wheat bread for its beneficial health effects. All the analyses were made in crust parts of the samples. The aim of the present study was to develop a rapid and reliable LC-MS/MS method to determine acrylamide levels of different bread types, like wheat bread, whole bread and bran bread. Besides, reducing sugar content, protein content, moisture content, $\mathrm{pH}$, and colour parameters $\left(\mathrm{L}^{*}, \mathrm{a}^{*}, \mathrm{~b}^{*}\right)$ were determined in crust parts of all bread samples and correlations between acrylamide content and these parameters were investigated.

\section{Materials and methods}

\subsection{Materials}

1.1.1. Samples. Thirty wheat bread, thirty bran bread, and twenty-five whole wheat bread samples were purchased from local bakeries in Izmir (the biggest city in the Aegean region of Turkey). All bread samples were separated into crusts and crumbs. Crust parts of the samples were homogenized and stored at $-18^{\circ} \mathrm{C}$ until analysis. Acrylamide analysis was also done in the crumb part of different bread samples, and acrylamide was not detected in this part of bread. Acrylamide was formed in the crust part of bread samples. ACAR and GöKMEN (2009) studied the effects of the change of temperature in different locations of the sample influenced by the product thickness. The temperature values were close to each other in the sample having a thickness of $1 \mathrm{~mm}$ (crust model). These findings were in accordance with ours. So we decided to make the analyses in crust parts of samples. Crust amount/crumb amount of samples (mean values) were calculated as $0.98 \pm 0.13$ for wheat bread; $1.08 \pm 0.18$ for bran bread, and $0.83 \pm 0.16$ for whole wheat bread.

1.1.2. Reagents. Acrylamide was obtained from Sigma (Steinheim, Germany). 2,3,3- $\mathrm{D}_{3}$ labelled acrylamide $\left(\mathrm{D}_{3}-\mathrm{AA}\right.$, isotopic purity $>98 \%$ ) as internal standard was obtained from Polymer Source (Toronto, Canada). Glucose, fructose, potassium hexacyanoferrate trihydrate, hexane, zinc sulphate heptahydrate, formic acid, and hydrochloric acid were supplied from Merck (Darmstadt, Germany) and acetonitrile (HPLC grade) was from Lab-Scan (Dublin, Ireland). HPLC grade water was supplied from VWR (EC). Standard stock solutions of acrylamide and $\mathrm{D}_{3}-\mathrm{AA}$ were prepared by dissolving the chemicals in acetonitrile. These stock solutions contained $250 \mu \mathrm{g}$ of acrylamide and $250 \mu \mathrm{g} \mathrm{D}$-AA in $1 \mathrm{ml}$, separately. For the solid phase extraction OASIS MCX cartridge $\left(3 \mathrm{~cm}^{3} / 60 \mathrm{mg}\right.$, Waters, Milford, Massachusetts, USA) was used. 


\subsection{Methods}

1.2.1. Acrylamide analysis. According to the developed method $0.025,0.05,0.125$, $0.25,0.625,1.25$, and $2.5 \mathrm{ml}$ of $1 \mathrm{mg} \mathrm{l}^{-1}$ acrylamide solutions were taken and $2 \mathrm{ml}$ of $1 \mathrm{mg} \mathrm{l}^{-1}$ $\mathrm{D}_{3}$-AA solution and $20 \mathrm{ml}$ of distilled water were added. Then $\mathrm{pH}$ of the solutions was adjusted to 2.3 by hydrochloric acid and diluted to $25 \mathrm{ml}$ with distilled water. Final concentration of $\mathrm{D}_{3}$-AA in all these solutions was $80 \mu \mathrm{g} \mathrm{l^{-1 }}$. This method was developed by modifying the method of Palazoğlu and co-workers (2010). Six grams of sample was homogenized in $30 \mathrm{ml}$ of distilled water, suspension was taken into a $100 \mathrm{ml}$ conical flask and shaken for $30 \mathrm{~min}$. The mixture was clarified by $1.5 \mathrm{ml} \mathrm{Carrez} \mathrm{I}\left(23 \%\right.$, w/v ZnSO $\left..7 \mathrm{H}_{2} \mathrm{O}\right)$ and $1.5 \mathrm{ml}$ Carrez II $\left(15 \% \mathrm{w} / \mathrm{v}, \mathrm{K}_{4} \mathrm{Fe}(\mathrm{CN})_{6} .3 \mathrm{H}_{2} \mathrm{O}\right)$ solutions and then the mixture was centrifuged at $10400 \mathrm{~g}$ for $15 \mathrm{~min}$. The supernatant was collected and defatting was performed by using $20 \mathrm{ml}$ of hexane. Twenty $\mathrm{ml}$ of the aqueous phase was taken and $2 \mathrm{ml}$ of $1 \mathrm{mg} \mathrm{l}^{-1} \mathrm{D}_{3}$-AA was added. This sample was treated with hydrochloric acid to obtain a $\mathrm{pH}$ of 2.3 and diluted to 25 $\mathrm{ml}$ with distilled water. For the optimization of purification step, OASIS HLB cartridge was used, but the best chromatogram was obtained by OASIS MCX cartridge. So Waters OASIS MCX SPE cartridge (New York, USA) was used for further clean-up. The pass through strategy for the SPE clean-up was applied to retain the matrix interferences (Liu et al., 2008). OASIS MCX cartridge was conditioned consecutively with $1 \mathrm{ml}$ of methanol and $1 \mathrm{ml}$ water at a rate of one drop per second. Air was passed through the cartridge by pushing the injector to remove the remaining water. One $\mathrm{ml}$ of extract was passed through the cartridge at a rate of one drop per second. The first 10 drops of eluate were discarded while the remaining drops were collected in a vial and $15 \mu \mathrm{l}$ of the sample was injected to LC-MS/MS. Analysis was performed in duplicate.

1.2.2. Chromatographic conditions. Mobile phase was prepared by mixing solvent $A$ and solvent B in a ratio of 90:10 (v/v), respectively. Solvent A was $0.3 \%(\mathrm{v} / \mathrm{v})$ aqueous formic acid solution and solvent $\mathrm{B}$ was acetonitrile. The analytical separation was performed on a Zorbax column $\mathrm{C}_{18}(50 \mathrm{~mm} \times 4.6 \mathrm{~mm}, 1.8 \mu \mathrm{m}$, Santa Clara, USA) using the isocratic mixture at a flow rate of $0.8 \mathrm{ml} \mathrm{min}{ }^{-1}$ at $25^{\circ} \mathrm{C}$ with an injection volume of $15 \mu 1$. Stop time was $2 \mathrm{~min}$. For the optimization of chromatographic conditions, injection volume was evaluated and increased to $15 \mu 1$ to obtain higher signals. Different mobile phase compositions were examined and by acidifying the mobile phase, signal values were also increased.

1.2.3. Apparatus. Chromatographic separations were performed by using Agilent 1200 liquid chromatograph (Santa Clara, USA) connected to 6410 triple quad MS-MS detector with electrospray ionization in the positive-ion mode, equipped with a quaternary pump, an autosampler, and a temperature-controlled column oven. Data acquisition was performed in selected ion monitoring (SIM) mode. Multiple reaction monitoring (MRM) of transition ions was $\mathrm{m} / \mathrm{z} 72.0 \rightarrow 55.0$ for acrylamide and $\mathrm{m} / \mathrm{z} 75.1 \rightarrow 58.0$ for $\mathrm{D}_{3}-\mathrm{AA}$. For identifying acrylamide $\mathrm{m} / \mathrm{z} 72.0 \rightarrow 54.0$ ion was also monitored. Ion ratios of primary $(\mathrm{m} / \mathrm{z}=55.0)$ and secondary ion $(\mathrm{m} / \mathrm{z}=54.0)$ transitions were found as 68.3 for standard solutions, 67.0 for samples, and 69.6 for spiked samples. The optimized MS instrument parameters were drying gas temperature $\left(\mathrm{N}_{2}\right)$ of $350{ }^{\circ} \mathrm{C}$ with a flow rate of $121 \mathrm{~min}^{-1}$, nebulizer pressure of $275.8 \mathrm{kPa}$, capillary voltage of $4 \mathrm{kV}$, fragmentor voltage of $60 \mathrm{~V}$ for $\mathrm{D}_{3}-\mathrm{AA}$ and $70 \mathrm{~V}$ for acrylamide, collision energy of $10 \mathrm{~V}$ for each transition. Fragmentor voltage was evaluated for acrylamide and $\mathrm{D}_{3}-\mathrm{AA}$ determination and optimum conditions were determined as given above. The 
concentration of acrylamide in bread samples was determined by a calibration curve, which was daily prepared by plotting peak area ratios of the analyte acrylamide, i.e., 55 to the $\mathrm{D}_{3}$ AA, i.e. 58 versus amount of acrylamide injected.

1.2.4. Determinations of protein, reducing sugar, moisture, $\mathrm{pH}$, and colour. Protein analysis was performed in duplicate according to A.O.A.C. (2000). Reducing sugar contents (glucose+fructose) were determined in duplicate according to IHC (International Honey Commission) 2002 method with some modifications (IHC, 2002). The $\mathrm{pH}$ values of crust parts of bread samples were measured with a digital $\mathrm{pH}$ meter in triplicate (TS, 2010). Moisture contents of crust parts of bread samples were measured according to TS 1135 ISO 712 in triplicate (TS-ISO, 2001). CIE colour parameters (L*, a*, b*) of crust parts of bread samples were measured by Hunter Lab Colorimeter (Model Colorflex, Virginia, USA) as four replicates.

1.2.5. Statistical analysis. Statistical analyses were realised with the SPSS 16.0 statistics package programme.

\section{Results and discussion}

An accurate, practical, and non-toxic LC-MS/MS method was used for trace determination of acrylamide in bread. The chromatograms of fragment ion $\mathrm{m} / \mathrm{z} 55.0$ for acrylamide in standard solution and bread (crust) sample are demonstrated in Fig. 1. As it is seen from Fig. 1 , interfering compounds were completely eliminated by optimizing the sample preparation and purification steps and by optimizing chromatographic conditions. Data for calibration curve were collected using triplicate responses for 7 concentrations. Linearity was observed up to $750 \mu \mathrm{g} \mathrm{kg}^{-1}$ food with a determination coefficient of 0.999 . Recovery rate was found 99.3\% with limit of detection (LOD) and limit of quantification (LOQ) values of $1.5 \mu \mathrm{g} \mathrm{kg}^{-1}$ and $5.0 \mu \mathrm{g} \mathrm{kg}^{-1}$, respectively. Certified reference materials of crisp bread with T-3021 and T-3026 reference codes supplied by FAPAS (UK) were analysed. Acrylamide contents of these samples were found in the range cited in the certificates. The developed method was successfully applied to bread and other bakery products in our laboratory.
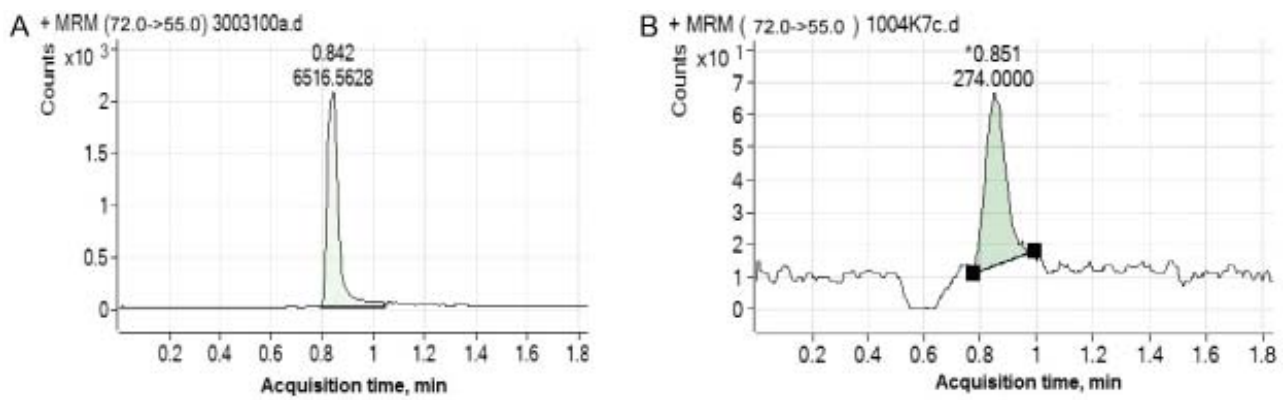

Fig. 1. LC-MS/MS chromatograms of acrylamide fragment ion m/z 55.0 A) in standard acrylamide solution $\left(100 \mu \mathrm{g}^{-1}\right)$; B) in bread sample (crust)

Concentrations of acrylamide in 30 wheat bread samples from different manufacturers are shown in Table 1. As is seen in the table, acrylamide contents of wheat bread samples 
varied from $14.43 \mu \mathrm{g} \mathrm{kg}^{-1}$ to $42.92 \mu \mathrm{g} \mathrm{kg}^{-1}$ with an average content of $28.97 \mu \mathrm{g} \mathrm{kg}^{-1}$. Protein, reducing sugars, moisture, $\mathrm{pH}$, and colour values of wheat bread samples were determined and tabulated in Table 1. According to the Pearson correlation test, positive correlations were obtained between acrylamide contents and fructose contents, and total reducing sugar contents of wheat bread samples $(\mathrm{P}<0.05)$. No statistically significant correlations were obtained between acrylamide contents and protein contents, glucose contents, moisture contents, $\mathrm{pH}$ values, $\mathrm{a}^{*}$ and $\mathrm{b}^{*}$ values of wheat bread samples $(\mathrm{P}>0.01, \mathrm{P}>0.05)$. According to the Pearson correlation test, a negative correlation was obtained between acrylamide contents and $\mathrm{L}^{*}$ values of wheat bread samples $(\mathrm{P}<0.05)$. Correlation between acrylamide contents and $\mathrm{L}^{*}$ was in agreement with the results of VIKLUND and co-workers (2010). Concentrations of acrylamide in 30 bran bread samples from different manufacturers are shown in Table 2. As is seen in the table, acrylamide contents of bran bread samples varied from $16.07 \mu \mathrm{g} \mathrm{kg}^{-1}$ to $79.11 \mu \mathrm{g} \mathrm{kg}^{-1}$ with an average content of $41.39 \mu \mathrm{g} \mathrm{kg}^{-1}$. Protein, reducing sugars, moisture, $\mathrm{pH}$, and colour values of bran bread samples were determined and tabulated in Table 2 . According to the Pearson correlation test, a positive correlation was obtained between acrylamide contents and $\mathrm{pH}$ values of bran bread samples $(\mathrm{P}<0.05)$. No statistically significant correlations were obtained between acrylamide contents and protein contents, glucose contents, fructose contents, total reducing sugar contents, moisture contents, $\mathrm{L}^{*}, \mathrm{a}^{*}$, and $\mathrm{b}^{*}$ values of bran bread samples $(\mathrm{P}>0.01, \mathrm{P}>0.05)$. Concentrations of acrylamide in 25 whole wheat bread samples from different manufacturers are shown in Table 3 . As is seen in the table, acrylamide contents of whole wheat bread samples varied from $20.62 \mu \mathrm{g} \mathrm{kg}^{-1}$ to 49.99 $\mu \mathrm{g} \mathrm{kg}^{-1}$ with an average content of $35.87 \mu \mathrm{g} \mathrm{kg}^{-1}$. Protein, reducing sugars, moisture, $\mathrm{pH}$, and colour values of whole wheat bread samples were determined and tabulated in Table 3 . No statistically significant correlations were obtained between acrylamide contents and protein contents, fructose contents, total reducing sugar contents, $\mathrm{L}^{*}, \mathrm{a}^{*}$, and $\mathrm{b}^{*}$ values in whole wheat bread samples $(\mathrm{P}>0.01, \mathrm{P}>0.05)$. According to the Pearson correlation test, positive correlations were obtained between acrylamide contents and glucose contents, and $\mathrm{pH}$ values of whole wheat bread samples $(\mathrm{P}<0.01)$. According to the Pearson correlation test, a negative correlation was obtained between acrylamide contents and moisture contents of whole wheat bread samples $(\mathrm{P}<0.05)$. This finding was in accordance with the results of SADD and coworkers (2008) in bakery products and VIKLUND and co-workers (2010) in fried potatoes. These findings on the correlation of different parameters change with different matrices. For example, a correlation between acrylamide and colour parameters could be found for smallsurface materials, while for large-surface material no correlation is observed.

PALAzoĞLu and co-workers (2010) used formic acid for extraction of acrylamide, and OASIS MCX cartridge for clean-up. Nevertheless, their extraction procedure was not suitable for MS/MS detection causing split peaks for acrylamide. LiU and co-workers (2008) studied acrylamide contents of tea samples by LC-MS/MS method using OASIS MCX cartridge for clean-up. A long-lasting extraction procedure was used; recovery rates of their study were low. These results were similar with the results of CHEN and co-workers (2008). ARISSETO and co-workers (2009) studied acrylamide contents of cacao and coffee samples by LC-MS/MS method using OASIS HLB and Bond Elut-accucat cartridges for clean-up. Two steps cleanup caused an increase in cost and time of analysis.

In this study, a modified new LC-MS/MS method was used. There was no interference problem in our method. As it offers the advantage of being able to analyse acrylamide without derivatization, LC-MS/MS method was preferred to be developed, thus simplifying the sample preparation step and shortening the analysis time. A reliable method of analysis 


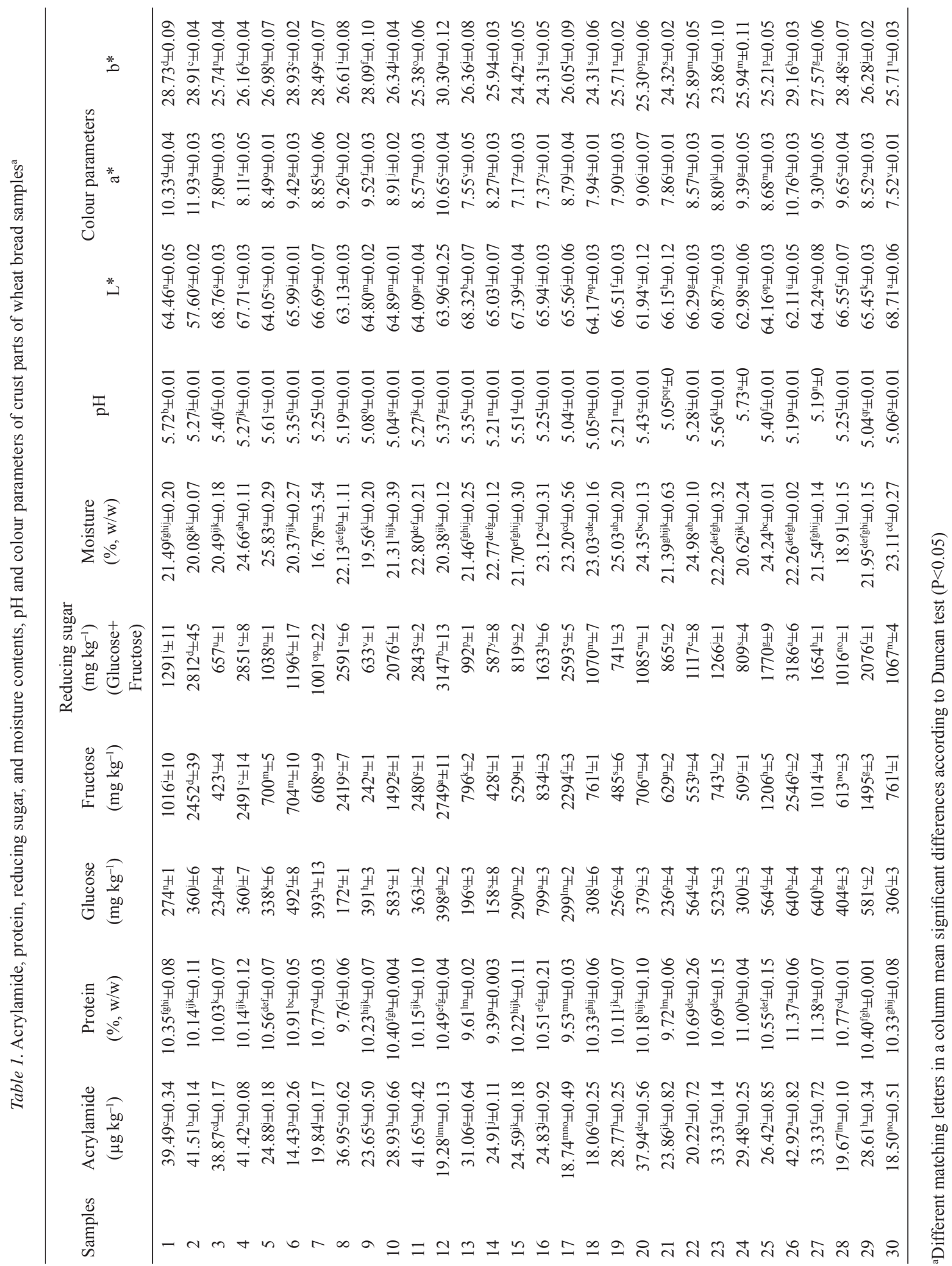




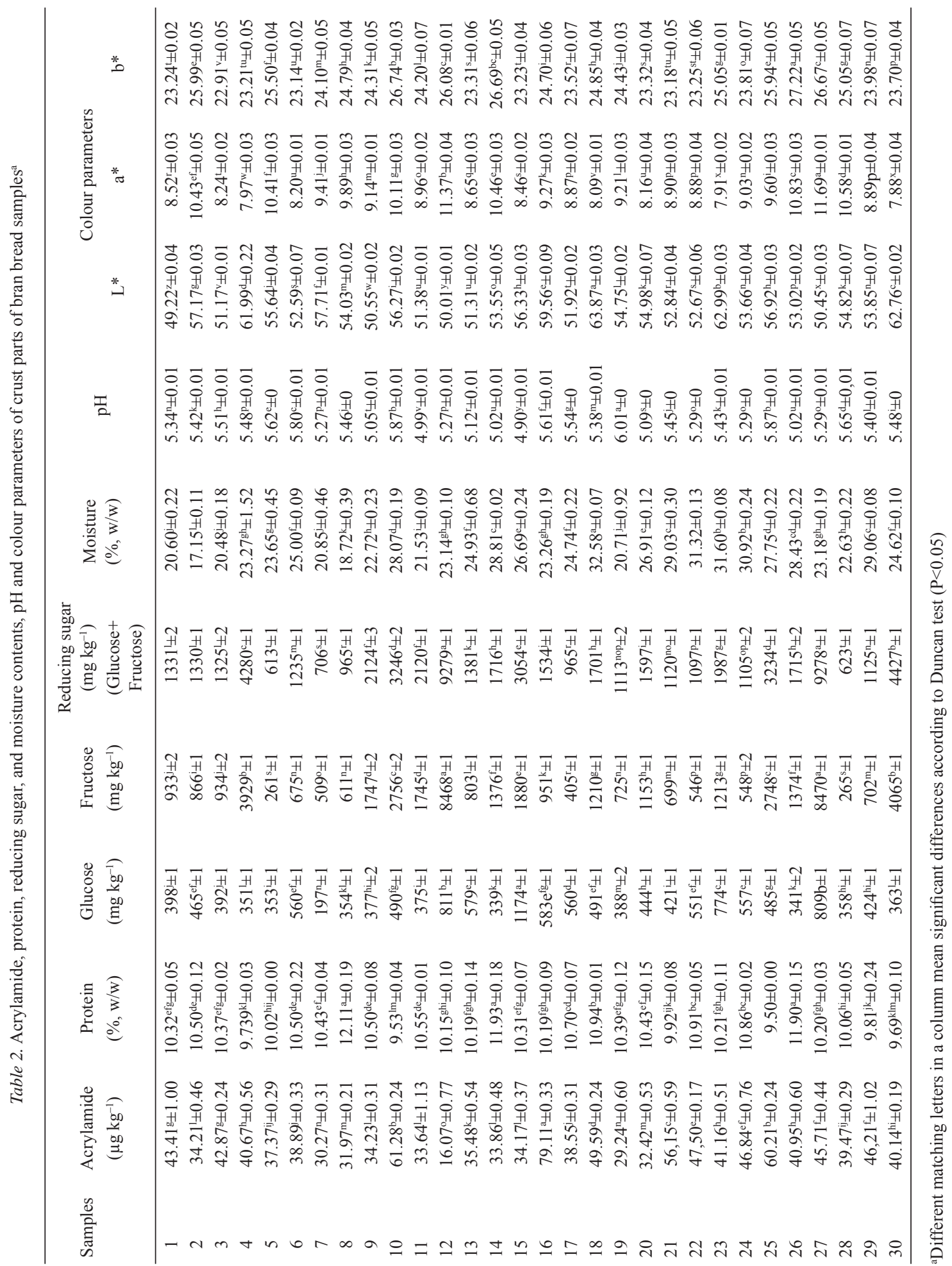




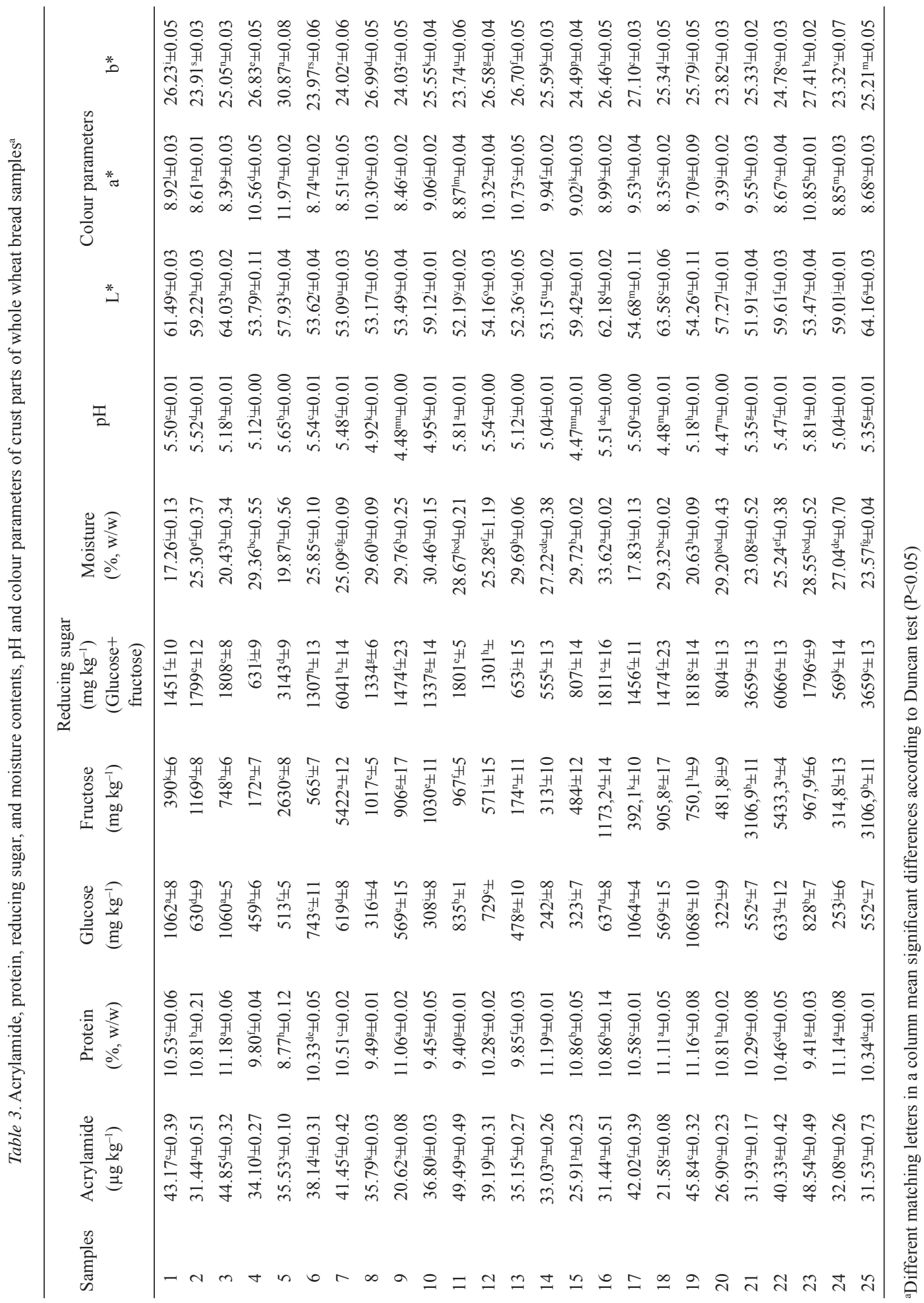


should be used to determine the content of acrylamide in foods. A rapid, accurate, precise, and non-toxic LC-MS/MS method was developed for trace determination of acrylamide in bread. This work is the first survey study for the determination of acrylamide contents of different breads produced in Turkey by LC-MS/MS method.

\section{Conclusion}

A rapid and reliable LC-MS/MS method was developed for the determination of acrylamide in three different bread types; wheat bread, bran bread, whole wheat bread. The method was linear up to $750 \mu \mathrm{g} \mathrm{kg}^{-1}$ food with a determination coefficient of 0.999 . Recovery rate was found $99.3 \%$ with limit of detection and limit of quantification values of $1.5 \mu \mathrm{g} \mathrm{kg}^{-1}$ and 5.0 $\mu \mathrm{g} \mathrm{kg}{ }^{-1}$, respectively. Acrylamide levels of bread samples were found lower when compared with foods such as French fries, potato chips, and potato crisps. According to the mean acrylamide contents of 3 different types of breads, bran bread samples contained higher amount of acrylamide.

The authors want to thank to Turkish Ministry of Food, Agriculture and Livestock (Project No: TAGEM/ $\mathrm{GY} / 10 / 03 / 01 / 165)$ for financial support.

\section{References}

ACAR, O.C. \& GÖKMEN, V. (2009): Investigation of acrylamide formation on bakery products using a crust-like model. Mol. Nutr. Fd Res., 53, 1521-1525.

A.O.A.C. (2000): Official Methods of Analysis, $17^{\text {th }}$ ed., Maryland, USA. No. 990.03.

Arisseto, A.P., Toledo, M.C.F., Govaert, Y., Loco, J.V., Fraselle, S., Degroodt, J. \& Caroba, D.C.R. (2009): Contribution of selected foods to acrylamide intake by a population of Brazilian adolescents. LWT-Food Sci. Technol., 42, 207-211.

BARUtÇU, I., ŞAHIN, S. \& Sumnu, G. (2009): Acrylamide formation in different batter formulations during microwave frying. LWT - Fd Sci. Technol., 42, 17-22.

Chen, F., Yuan, Y., Liu, J., Zhao, G. \& Hu, X. (2008): Survey of acrylamide levels in Chinese foods. Food Addit. Contam. B, 1(2), 85-92.

Claeys, W.L., Vleeschouwer, K.D. \& Hendrickx, M.E. (2005): Quantifying the formation of carcinogens during food processing: Acrylamide. Trends Fd Sci. Technol., 16, 181-193.

Grob, K. (2007): Options for legal measures to reduce acrylamide contents in the most relevant foods. Food Addit. Contam. Suppl. 1. 24, 71-81.

IARC (1994): Acrylamide. In some industrial/chemicals; IARC monographs on the evaluation of carcinogenic risks to humans; International Agency for research on cancer, Lyon, France, 60, p. 389.

IHC (2002): Harmonised methods of the International Honey Commission. IHC (International Honey Commission), Switzerland, 62 pages.

Liu, J., Zhao, G., Yuan, Y., Chen, F. \& Hu, X. (2008): Quantitative analysis of acrylamide in tea by liquid chromatography coupled with electrospray ionization tandem mass spectrometry. Food Chem., 108, 760-767.

PalazoĞLu, T.K., Savran, D. \& GöKmen, V. (2010): Effect of cooking method (baking compared with frying) on acrylamide level of potato chips. Soc. Fd Sci. Technol., 75, 25-29.

Pedreschi, F., KaAcK, K. \& Granby, K. (2006): Acrylamide content and color development in fried potato strips. Food Res. Int., 39, 40-46.

SAdD, P.A., Hamlet, C.G. \& Liang, L. (2008): Effectiveness of methods for reducing acrylamide in bakery products. J. Agric. Fd Chem., 56, 6154-6161.

TS-ISO (2001): Tahıl ve tahıl ürünleri - Rutubet muhtevasi tayini rutin referans metot. Cereals and cereal productsReference method for the determination of moisture content. Institute of Turkish Standards, Ankara. TS 1135 ISO 712 
TS (2010): Milföy Hamaru (Yaprak Hamaru) (Puff Dough), Institute of Turkish Standards, Ankara. TS12230 Viklund, G.A., Olsson, K.M., SјöHolm, I.M. \& SkOG, K.I. (2010): Acrylamide in crisps: Effect of blanching studied on long-term stored potato clones. J. Food Compos. Anal., 23, 194-198.

Wenzl, T., De La Calle, B.M. \& Anklam, E. (2003): Analytical methods for the determination of acrylamide in food products; a review. Food Addit. Contam., 20, 885-902.

Zhang, Y. \& ZhANG, Y. (2007): Formation and reduction of acrylamide in Maillard reaction: A review based on the current state of knowledge. Crit. Rev. Food Sci., 47, 521-542. 